\section{Bumblebees ...}

Bumblebees. By D. V. Alford. Pp. xii + $352+48$ plates. (Davis-Poynter: London, June 1975.) £25.

\section{Sorry, for copyright reasons some images on this page may not be available online}

Bumblebees hold a particular fascination for the entomologist because of their social organisation and because they are important pollinators of the native flora and many of our crops. Consequently, their biology has been studied in depth and several monographs have been devoted to them, to which Dr Alford's comprehensive and up-to-date account is a welcome addition.

The layout of the book is good. There is a brief introduction outlining bumblebee anatomy and physiology followed by the three main parts of the book. Part I includes chapters on various biological aspects of colony life, including hibernation, colony initiation and development. The author has confined himself largely to nest biology and says relatively little of their foraging behaviour and ecological importance as pollinators. The author's particular interest is reflected in the large section devoted to the parasites and predators of bumblebees. Part II deals primarily with the British species; each is described with information on their classification, habits and distribution. In Part III methods of collecting individual bumblebees and of locating, transferring and housing their nests for observation are outlined. The appendix presents 26 distribution maps of the British species of bumblebees as prepared by the Biological Records Centre for the Bumblebee Distribution Maps Scheme, for which Dr Alford is collating data sent in by members of the Bee Research Association. A discussion of how the distribution of different species is changing would have been interesting but perhaps little is known. Lists of all the plant and animal species mentioned in the text are given and there are comprehensive author, plant and animal indices and a bibliography of over 500 references to original papers.

The book is copiously illustrated with 26 colour plates, 63 black and white plates and over 200 line drawings. The photographs are, however, disappointing. In his determination to present photographs of all the British species, the author has included many of poor quality. The line drawings are clearly drawn and enhance the text, although many of them would appear more attractive if they had been reduced in size.

The volume is expensive. It will certainly be too highly priced for many individual pockets but should be a useful addition to specialist libraries.

Ingrid $\mathrm{H}$. Williams

\section{... and beetles}

The Life of Beetles. Glyn Evans.

Pp. 232. (Allen and Unwin: London, June 1975.) $£ 6.90$.

As one of my mentors used to say, "God made too many beetles". Until now there has been no book on the general biology of beetles in English, and such a book is therefore bound to fill a need. Dr Evans has not, however, written an impressive book. Much more information about them can be conveyed in 200 pages even without the use of "specialist jargon", the absence

\section{Sorry, for copyright reasons some images on this page may not be available online}

Lucanus cervus (stag beetle), from a drawing made in 1805 of which sometimes does duty here for a lack of knowledge. The book lacks balance. For instance, more than a sixth of the text is a chapter on food and feeding habits. Here we find nothing about the vitamin, amino acid, and other nutritional requirements of beetles nor about the role of gut and intracellular symbionts or how beetles utilise such materials as cellulose and keratin. Some of the illustrations are good, but a few are exceptionally poor (for example, Fig. 3). The references are at the end of the book, but for some reason they are cited separately for each chapter. One consequence of this is that in a meagre bibliography no less than 15 titles occur two or even three times in seven pages. In a section "Further Reading" no less than nine titles from the bibliography are repeated, sometimes twice.

Sorry, for copyright
reasons some images
on this page may not
be available online

In the introduction and elsewhere the role of the hard and rigid body-wall cuticle in the success of beetles is heavily stressed, but most beetles are larvae and most larval beetles have a soft and flexible body-wall. Taenidial thickenings are not lost in the finer branches of the tracheae (p. 51): they are present even to the ends of the tracheoles. The visible spectrum of insects does not end at blue-green (p. 43) but extends from far below 300 to about $750 \mathrm{~nm}$ in a few. No other group of animals has so wide a spectrum. The larvae of the Dryopidae are said to be aquatic (p. 29), but there is no authentic instance of an aquatic larva in this family. In the Hydrophilidae silk is not produced by the Malpighian tubes (p. 68) but is secreted by colleterial glands. $\mathrm{He}$ suggests (p. 68) that the funnel of the cocoon of Hydrophilus is a "tail-piece" of no functional significance, but it was long ago shown that it enables the embryos and young larvae to use atmospheric oxygen while the cocoon is covered by water.

There is a very real need for a book on the biology of beetles that combines wide personal knowledge of the animals with extensive reading. The desire to write a book on beetles is not of itself enough.

H. E. Hinton 